Methods As part of 'The eTEST Project', an integrative information technology package was developed containing an electronic risk assessment, clinician prompts to offer testing, SMS testing recalls, and electronic auditing functions. The software was introduced progressively starting in November 2011 with meeting and field notes gathered during clinic visits before, during and after implementation. Using these data, a thematic analysis was undertaken with a focus on identifying the challenges of introducing new technology in a clinical context.

Results Three dominant themes were identified in the meeting and field note data. The first of these, 'time management', describes the perceived risks to time-efficient consults that doctors and staff feared employing a new tool and collecting additional information could pose. Second, 'administrative limitations', a theme most common among practise managers, raises issues of increased demand on already burdened administrative supports. The final theme, 'technological requirements', is characterised by doctor's concerns over the additional burden of learning and using new software and troubleshooting technical issues.

Conclusions The results highlight common concerns and fears among clinical staff around the use of new technologies in general practise. Not only does this provide an opportunity for comparisons with the traditional hurdles to clinical health interventions but it is also the first step towards overcoming such obstacles. More broadly, these findings can inform future technology interventions of a similar nature in general practise.

\section{P6.018 PARTICIPATORY ACTION RESEARCH, EVIDENCE-BASED PUBLIC HEALTH, AND COOPERATIVE AGREEMENTS: ADVERSE EFFECTS}

doi:10.1136/sextrans-2013-051184.1172

W W Darrow. Florida International University, Miami, FL, United States

Background Racial and Ethnic Approaches to Community Health (REACH) 2010 was an ambitious multi-sector, multilevel, multicenter, and multi-phased community demonstration project designed to reduce health disparities in the United States. Requirements for a cooperative agreement with the Centers for Disease Control and Prevention were enumerated in Program Announcement 99064. Applicants had to represent coalitions of predominantly minority community members that would propose community action plans (CAPs) to address one or more serious health problems affecting one or more minority populations. The Broward Coalition to Eliminate Disparities in HIV Disease was one of 32 (out of 206) eligible applicants to receive a competitive award in Fiscal Year 2000 to develop a CAP. The CAP was one of 24 to be approved by CDC for implementation in Fiscal Year 2001. The primary goal was to eliminate disparities in new HIV infections reported among Black and Hispanic residents of Broward County by 2010 .

Methods A case study to illustrate how competing models of disease prevention can inhibit successful outcomes in public health.

Results The participatory action research (PAR) programme designed, developed, and implemented by the Broward Coalition contained four interventions chosen by members after systematically working through the PRECEDE Health Promotion Planning Model. From 1999 through 2006, rates of new HIV infections among non-Hispanic Black residents of Broward declined from 193/100,000 to 81/100,000. On April 5, 2005, CDC site visitors informed the Coalition that funding for Broward would be cut in half in Fiscal Year 2006. They urged that only interventions recommended by CDC experts as "high impact" be continued. Subsequently, educational outreach efforts considered essential by local community members were curtailed and rates of new HIV infections among Blacks in Broward began to rise.
Conclusion Project shortcomings were linked to the decrement of resources and reinterpretation of PAR interventions by evidencebased criteria.

\section{P6.019 PREVENTING MOTHER TO CHILD TRANSMISSION OF HIV: CHALLENGES TO IMPLEMENTING WHO GUIDELINES}

doi:10.1136/sextrans-2013-051184.1173

${ }^{1}$ E du Plessis, 'S Y Shaw, ${ }^{2 M}$ Gichuhi, ${ }^{3} \mathrm{~J}$ Kimani, 'L Gelman, 'R Lester, 'L S Avery. ${ }^{1}$ University of Manitoba, Winnipeg, MB, Canada; ${ }^{2}$ University of Nairobi, Kenya, Kenya; ${ }^{3}$ University of Nairobi, Nairobi, Kenya

Background In 2009 the WHO provided updated guidelines for prevention of mother to child transmission (PMTCT) of HIV. Although the guidelines are based on the best available evidence and have the potential to reduce transmission, challenges remain in implementation. Data from Kenya illustrated that other factors may complicate the implementation of these guidelines.

Methods HIV-positive, pregnant women were recruited from two maternity hospitals in Nairobi, Kenya. Information was collected from participants (505 women to date) with surveys at baseline as well as 48 hour follow up as part of a study on the use of mobile technology in PMTCT programmes. Questions included socioeconomic characteristics, history of current/previous pregnancies, knowledge of PMTCT and Nevirapine use.

Results At presentation the majority of women were between 21 and 28 weeks pregnant (51.7\%) with only $11.7 \%$ under 20 weeks gestational age. Although $60.5 \%$ of the women reported disclosing their status to their partners immediately, a quarter had not disclosed or refrained from answering. At 48 hour follow up, more than half the women $(56.7 \%)$ reported attending four or more antenatal visits. Of the women, $71 \%$ reported receiving Nevirapine during labour while $91.9 \%$ of infants reportedly received Nevirapine. No significant difference was found between hospitals.

Conclusion In our sample, a higher number of women had disclosed to their partners than previously suggested, but there were still a significant number of women who had not disclosed, reducing the chance of male involvement in counselling. Although over $70 \%$ of women reported receiving Nevirapine during labour, the high percentage of women who present for their first visit after 14 weeks suggests that the use of AZT, as stated in the guidelines, is not feasible. Almost half the women did not attend four antenatal visits, suggesting that other factors may need to be considered for effective PMTCT.

\section{P6.020 THE LOCAL FINANCE EVALUATORS (LFES) AS A REAL-TIME STRATEGY TO IMPROVE FINANCIAL MANAGEMENT AT THE SR-LEVEL IN THE CONTEXT OF IMPLEMENTING A REGIONAL GLOBAL FUND PROGRAM ON HIV-AIDS}

doi:10.1136/sextrans-2013-051184.1174

L P Norella. ISEAN Hivos Program, Jakarta, Indonesia

Background The ISEAN-Hivos Program is a Global Fund HIV Program focusing on MSMs and Transgenders in Indonesia, Malaysia, Philippines and Timor Leste. To create an internal system within the Program which can cross-check the financial data generated by the Sub-Recipients (SRs), a team of Local Finance Evaluators were engaged. The LFEs represent an added layer of financial accountability developed by Program as a financial management diligence initiative. It also has an additional advantage of providing real time regular feedback and mentoring to the SRs.

Methods The data for this presentation was based on a review of the SR documents submitted by the LFEs to Hivos, as Principal Recipient. Additional feedback was also gathered from the LFEs themselves, as well as other programme staff. 